\title{
Thermogravimetry and Reaction Gas Analysis of the Carbothermic Reduction of Titanomagnetite Ores with Char
}

\author{
Sung-Mo JUNG* \\ Graduate Institute of Ferrous Technology, POSTECH, Pohang, 790-784 Korea. \\ (Received on August 28, 2013; accepted on December 15, 2013)
}

\begin{abstract}
The carbothermic reduction of titanomagnetite (TTM) was investigated from a kinetic viewpoint in the temperature range of 1000 to $1150^{\circ} \mathrm{C}$ employing thermogravimetric analysis (TGA) and quadruple mass spectrometry (QMS). The method of evaluating the fractional reduction in the carbothermic reduction of TTM by TGA was validated. The carbon in char consumed for the reduction of TTM was fully gasified into $\mathrm{CO}$ and $\mathrm{CO}_{2}$, which indicates that the TGA can be coupled to QMS from the viewpoint of mass balance of carbon. The carbon gasification reaction was activated when the $\mathrm{Fe}_{3} \mathrm{O}_{4}$ in $\mathrm{TTM}$, wustite and Fe coexist at the fractional reduction of 0.21 , indicating that Fe-catalyzed nature of Fe was confirmed for the carbon gasification. The activation energy for the reduction in TTM to wustite was evaluated to be $241 \mathrm{~kJ} / \mathrm{mol}$ and the initial reduction stage is believed to be limited by carbon gasification. In the current study, it was considered that the changeover in reaction mechanism might be carried out from carbon gasification to the reduction in wustite to $\mathrm{Fe}$ by $\mathrm{CO}$ during the isothermal reduction of TTM with char.
\end{abstract}

KEY WORDS: direct reduced iron (DRI); isothermal reduction; thermogravimetric analysis; quadruple mass spectrometry (QMS); carbon gasification; rate-controlling step.

\section{Introduction}

Due to the depletion of high quality hematite ores, it has been undertaken to utilize magnetite ores in the conventional blast furnace ironmaking or direct reduced iron (DRI) production. ${ }^{1)}$ The proportion of DRI usage in electric arc furnace (EAF) operation has been increasing because high quality and low-residual scrap, which had traditionally been used in EAFs to produce high quality steel, is in shortage. ${ }^{2)}$ The gas-based DR processes, such as, MIDREX or HYL III is becoming more and more competitive due to low price of shale gas. Nevertheless, coal-based DRI processes such as rotary kiln or rotary hearth furnace are still receiving great attention for producing flat products of steel using virgin iron. ${ }^{1)}$ However, extensive understanding of DRI production technology using magnetite ores is limited in alternative ironmaking processes.

The fundamental investigations on the kinetics and mechanism of carbothermic reduction of iron oxide were extensively carried out. $\mathrm{Rao}^{3)}$ found that the availability of $\mathrm{CO}$ governs the reduction process in hematite and carbon mixtures and that the carbon gasification reaction constitutes the rate limiting step for the overall process. Srinivasan and Lahiri ${ }^{4)}$ showed the continuous decrease in $\mathrm{CO}_{2} / \mathrm{CO}$ ratio during reduction, and that the activation energy of the reduction process has been found to decrease with progress in reduction, indicating a possible changeover in reaction mechanism. Fruehan ${ }^{5)}$ confirmed that the reduction of $\mathrm{Fe}_{2} \mathrm{O}_{3}$

* Corresponding author: E-mail: smjung@postech.ac.kr DOI: http://dx.doi.org/10.2355/isijinternational.54.781 to $\mathrm{FeO}$ takes place by means of the gaseous intermediates $\mathrm{CO}$ and $\mathrm{CO}_{2}$, and that the overall rate is controlled by the carbon oxidation by $\mathrm{CO}_{2}$. Szendrei and Berge ${ }^{6)}$ studied the reduction of hematite and graphite composite using thermogravimetric analysis and direct in situ analysis of reaction gases during reduction. Recently, Coetsee et al. ${ }^{7)}$ reported that the chemical reactions are under mixed control by the reduction of iron oxide and carbon gasification for average rate constants. Yang et al. ${ }^{8)}$ reported that the direct reduction at initial stage dominates carbothermic reduction of hematitegraphite composite and that it is determined by the indirect reduction together with the carbon gasification reaction. Chen et al. ${ }^{9)}$ showed that the metallization degree of titanomagnetite (TTM) concentrates are significantly improved by the pre-oxidation of titanomagnetite ores with pulverized coal.

Most of the previous researches about the carbothermic reduction of TTM were done using the weight change measured for the withdrawn pellet from the reaction chamber in the progress of reduction. Continuous change of fractional reduction of raw iron ores and char composite was not clearly evaluated in terms of the weight change by TGA. It is required to extensively understand the carbothermic reduction of titanomagnetite (TTM) for developing alternative ironmaking processes using magnetite ores without preliminary oxidation step. Therefore, the current research aims to more quantitatively investigate the kinetics and mechanisms of carbothermic reduction of TTM by char with the information about the compositions of the product gases with quadruple mass spectrometry (QMS). 


\section{Experimental}

\subsection{Materials Preparation}

The average sizes of original and pulverized TTM ores used for the experiments are about 190 and $80 \mu \mathrm{m}$, respectively. As shown in Fig. 1, the XRD pattern of the titanomagnetite represented major peaks for magnetite and traces of maghemite $\left(\gamma-\mathrm{Fe}_{2} \mathrm{O}_{3}\right)$. The peaks of Ti-rich phases such as ulvospinel $\left(\mathrm{Fe}_{2} \mathrm{TiO}_{4}\right)$, ilmenite $\left(\mathrm{FeTiO}_{3}\right)$ and rutile $\left(\mathrm{TiO}_{2}\right)$ were not detected, which is in good agreement with the results reported by Park et al. ${ }^{10)}$

Table 1 shows the chemical compositions of titanomagnetite mined in New Zealand. It is well known that the titanomagnetite ore is a solid solution of magnetite and ulvospinel as expressed by Eq. (1): ${ }^{10}$

$$
\left(\mathrm{Fe}_{3} \mathrm{O}_{4}\right)_{1-x}\left(\mathrm{Fe}_{2} \mathrm{TiO}_{4}\right)_{x}=\left(\mathrm{FeO} \cdot \mathrm{Fe}_{2} \mathrm{O}_{3}\right)_{1-x}\left(2 \mathrm{FeO} \cdot \mathrm{TiO}_{2}\right)_{x}
$$

Based on the compositions in Table 1, the mole fraction of ulvospinel in titanomagnetite, $x$ was evaluated to be 0.28 using Eqs. (2) and (3), which is in good agreement with $0.27 \pm$ 0.02 previously estimated by microscopic line mapping. ${ }^{10)}$

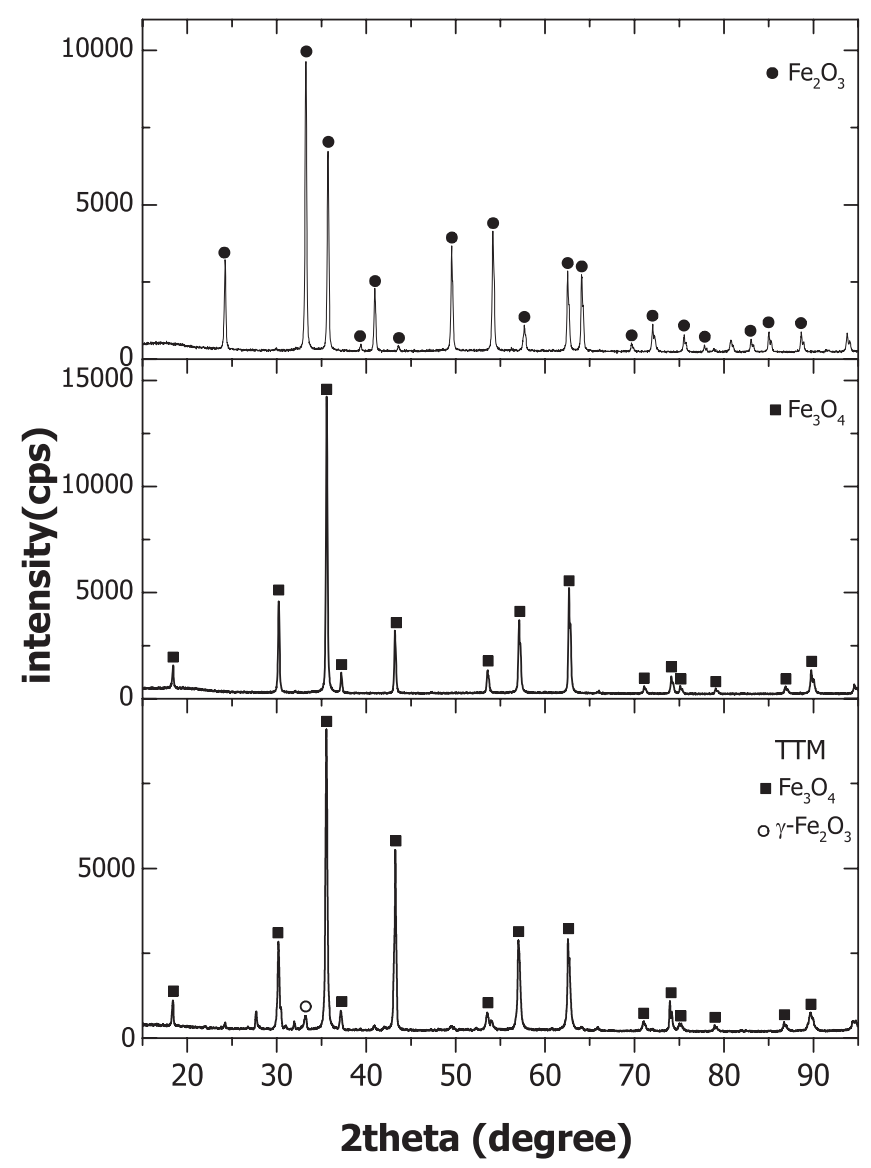

Fig. 1. XRD patterns of titanomagnetite ores used in the current study.

Table 1. Chemical compositions of raw titanomagnetite used in the present study (mass\%).

\begin{tabular}{ccccccccc}
\hline Total Fe & $\mathrm{FeO}$ & $\mathrm{Fe}_{2} \mathrm{O}_{3}$ & $\mathrm{SiO}_{2}$ & $\mathrm{Al}_{2} \mathrm{O}_{3}$ & $\mathrm{TiO}_{2}$ & $\mathrm{MgO}$ & $\mathrm{CaO}$ & $\mathrm{MnO}$ \\
\hline 57.79 & 28.65 & 50.78 & 3.31 & 3.67 & 7.00 & 3.32 & 1.63 & 0.45
\end{tabular}

$$
\begin{aligned}
& \text { Mole of } \mathrm{FeO}: \text { mole of } \mathrm{TiO}_{2}=(1+x): x \\
& \frac{\text { mass } \% \mathrm{FeO}}{M W_{\mathrm{FeO}}}: \frac{\text { mass } \% \mathrm{TiO}_{2}}{M W_{\mathrm{TiO}_{2}}}=(1+x): x
\end{aligned}
$$

where $M W_{\mathrm{i}}$ represents the molecular weight of component i. The char used in the current study was prepared by heating a coal at $950^{\circ} \mathrm{C}$ for $3 \mathrm{hrs}$ in $\mathrm{N}_{2}$ atmosphere and it was analyzed to contain 2.63 mass \% of volatile matter (VM) and 10.1 mass $\%$ of ash.

\subsection{Stoichiometric Mixing Ratio of TTM and Char}

From the weight percent of $\mathrm{FeO}$ and $\mathrm{Fe}_{2} \mathrm{O}_{3}$ shown in Table 1, the oxygen content combined with Fe was calculated to be about 21.64 mass\% by Eqs. (4) and (5), which is the theoretical loss in weight per $100 \mathrm{~g}$ of TTM for complete reduction:

$$
\begin{array}{r}
\mathrm{O} \text { in } \mathrm{FeO}=\left(\operatorname{mass} \% \mathrm{Fe}^{2+}\right) \times \frac{M W_{\mathrm{O}}}{M W_{\mathrm{Fe}}}=6.38 \text { mass } \% \ldots \\
\mathrm{O} \text { in } \mathrm{Fe}_{2} \mathrm{O}_{3}=\left(\operatorname{mass} \% \mathrm{Fe}^{3+}\right) \times \frac{3 M W_{\mathrm{O}}}{2 M W_{\mathrm{Fe}}}=15.26 \text { mass } \%
\end{array}
$$

In order to calculate the fractional reduction of TTM and char composite, it is necessary to estimate the stoichiometric amount of char required to reduce all the oxygen combined with Fe in the TTM in such a way that the molar ratio of carbon to oxygen $(\mathrm{C} / \mathrm{O}=1)$ is unity. That is, the following reduction reaction was considered taking into account that the TTM contains $0.2164 \mathrm{~g}$ in $1 \mathrm{~g}$ of TTM and that the fixed carbon of the char is 87.32 mass $\%$ :

$$
\begin{aligned}
& \text { Amount of required char }(\mathrm{g})= \\
& 0.2164 \mathrm{~g} \times \frac{M W_{\mathrm{C}}}{M W_{\mathrm{O}}} \times \frac{100}{87.32}=0.1859 \mathrm{~g}
\end{aligned}
$$

This results in the estimation of char amount to be $0.1859 \mathrm{~g}$ for reducing $1 \mathrm{~g}$ of TTM.

\subsection{Experimental Procedure}

Pulverized TTM of about $81 \mu \mathrm{m}$ and char of about $10 \mu \mathrm{m}$ were homogeneously mixed in the stoichiometric ratio using a ball mill. The pellets were formed into cylindrical shape (10 $\mathrm{mm}$ diameter and $7 \mathrm{~mm}$ height) weighing $1.5 \mathrm{~g}( \pm 0.01$ g) by a hydraulic press under the pressure of $50 \mathrm{MPa}$ for 1 min with distilled water added to ensure complete compactness. The pellets were air dried in an oven at $150^{\circ} \mathrm{C}$ before use. The pellet was placed into a cylindrical $\mathrm{Al}_{2} \mathrm{O}_{3}$ crucible (14 $\mathrm{mm}$ diameter, $20 \mathrm{~mm}$ height) which was then suspended and connected using a Pt wire to the balance part of a thermogravimetric analysis (TGA) apparatus (RUBOTHERM, Germany). The non-isothermal reduction was carried out by increasing temperature at $10^{\circ} \mathrm{C} / \mathrm{min}$ to target temperature. In addition, the isothermal reduction experiments were performed rapidly by heating up the TGA furnace at $100^{\circ} \mathrm{C} / \mathrm{min}$ to the target temperature in the temperature range of $1000-$ $1150^{\circ} \mathrm{C}$. The flow rate of Ar carrier gas was preliminarily determined to be $250 \mathrm{~mL} / \mathrm{min}$. The quantitative compositions of the reaction gases were continuously monitored by connecting TGA to the quadruple mass spectrometer (QMS, IPI-GAM400) preliminarily calibrated. 


\subsection{Evaluation of Fractional Reduction of TTM and Char Composite by TGA}

It is generally agreed that the reduction of iron oxide by carbon occurs through the gaseous intermediates $\mathrm{CO}$ and $\mathrm{CO}_{2}$ as represented by Eqs. (7) and (8). ${ }^{5}$ Under the assumption that all the $\mathrm{CO}$ gas generated by carbon gasification was used for the reduction in the titanomagnetite, the overall reduction can be expressed by Eq. (9):

$$
\begin{array}{r}
\mathrm{TTM}+\mathrm{CO}(g)=\text { reduced TTM }+\mathrm{CO}_{2}(g) \\
\mathrm{C}(s)+\mathrm{CO}_{2}(g)=2 \mathrm{CO}(g) \ldots \ldots \ldots \ldots . . . \\
\mathrm{TTM}+\mathrm{C}(s)=\text { reduced TTM }+\mathrm{CO}(g)
\end{array}
$$

The weight change by TGA consists of the weight changes of TTM and char based on the reduction by Eq. (9). That is, one oxygen atom in TTM is removed by one carbon atom in the reduction progress. Therefore, the weight change of TTM can be calculated in terms of the weight change of TGA by Eq. (12):

$$
\begin{gathered}
\Delta \mathrm{W}_{\mathrm{TGA}}=\Delta \mathrm{W}_{\mathrm{TTM}}+\Delta \mathrm{W}_{\text {char }} \\
\Delta \mathrm{W}_{\text {TTM }}: \Delta \mathrm{W}_{\text {char }}=16: 12 \ldots \\
\Delta \mathrm{W}_{\text {TTM }}=\Delta \mathrm{W}_{\text {TGA }} \times(16 / 28)
\end{gathered}
$$

The fractional reduction of TTM can be evaluated by the weight change of TTM with respect to the oxygen content combined with Fe in TTM as represented by Eq. (13).

$$
\begin{gathered}
\text { Fractional reduction }=\frac{\Delta W_{\mathrm{TTM}}}{W_{\mathrm{TTM}, \mathrm{i}} \times 0.2164} \ldots \ldots . . .(13) \\
W_{\mathrm{TTM}, \mathrm{i}}=W_{(\mathrm{TTM}+\mathrm{char}) \mathrm{i}} \times \frac{1}{1+0.1859} \ldots \ldots \ldots \ldots . .(14) \\
\text { Fractional reduction }=\frac{\Delta W_{\mathrm{TGA}} \times(16 / 28)}{W_{(\mathrm{TTM}+\text { char }), \mathrm{i}} \times \frac{1}{1+0.1859} \times 0.2164}
\end{gathered}
$$

Combination of Eqs. (12) to (14) provides the resulting equation, Eq. (15) for evaluating the fractional reduction of TTM and char composite with the information of the weight change of the pellet by TGA and the initial weight of pellet with the mixing ratio of TTM and char, $W_{(\mathrm{TTM}+\text { char),i. }}$.

In order to validate the method of evaluating the fractional reduction by Eq. (15), the procedure was applied to the carbothermic reduction of $\mathrm{Fe}_{3} \mathrm{O}_{4}$ and graphite composite. That is, Jung et al. ${ }^{11)}$ evaluated the fractional reduction for the samples withdrawn in the progress of the reduction in terms of the weight change of the pellet. Under the assumption that the total amount of reduction of iron oxides by $\mathrm{CO}$ is equal to the amount of the carbon gasification reaction, the overall reduction can be expressed as follows:

$$
\begin{gathered}
\mathrm{Fe}_{3} \mathrm{O}_{4}(s)+4 \mathrm{C}(s)=3 \mathrm{Fe}(s)+4 \mathrm{CO}(g) \ldots \\
\text { Fractional reduction }=\frac{\Delta W_{\mathrm{TGA}}}{W_{\left(\mathrm{Fe}_{3} \mathrm{O}_{4}+\text { graphite }\right), \mathrm{i}} \times M} .
\end{gathered}
$$

Following the identical procedure provides the fractional reduction which is similar to that by Rao. ${ }^{3)}$ In Eq. (17), $M$ corresponds to 0.4006 for the case of $\mathrm{Fe}_{3} \mathrm{O}_{4}$ since $M$ is equal to $4 M W_{\mathrm{CO}} /\left(M W_{\mathrm{Fe}_{3} \mathrm{O}_{4}}+4 M W_{\mathrm{C}}\right)$ in case the Reaction (16) goes to completion.

\section{Results and Discussion}

\subsection{Non-isothermal Reduction of Titanomagnetite (TTM) by Char}

Non-isothermal experiment was carried out to identify the temperatures of phase transformation in the progress of reduction as shown in Fig. 2. TTM started to be reduced when the temperature reached about $900^{\circ} \mathrm{C}$ and the reduction went to completion by the end of about 1-hour exposure at $1100^{\circ} \mathrm{C}$, which resulted in the fractional reduction of 0.84 . The reduction rate in the beginning of reduction was slow at low temperatures due to the relatively small rate

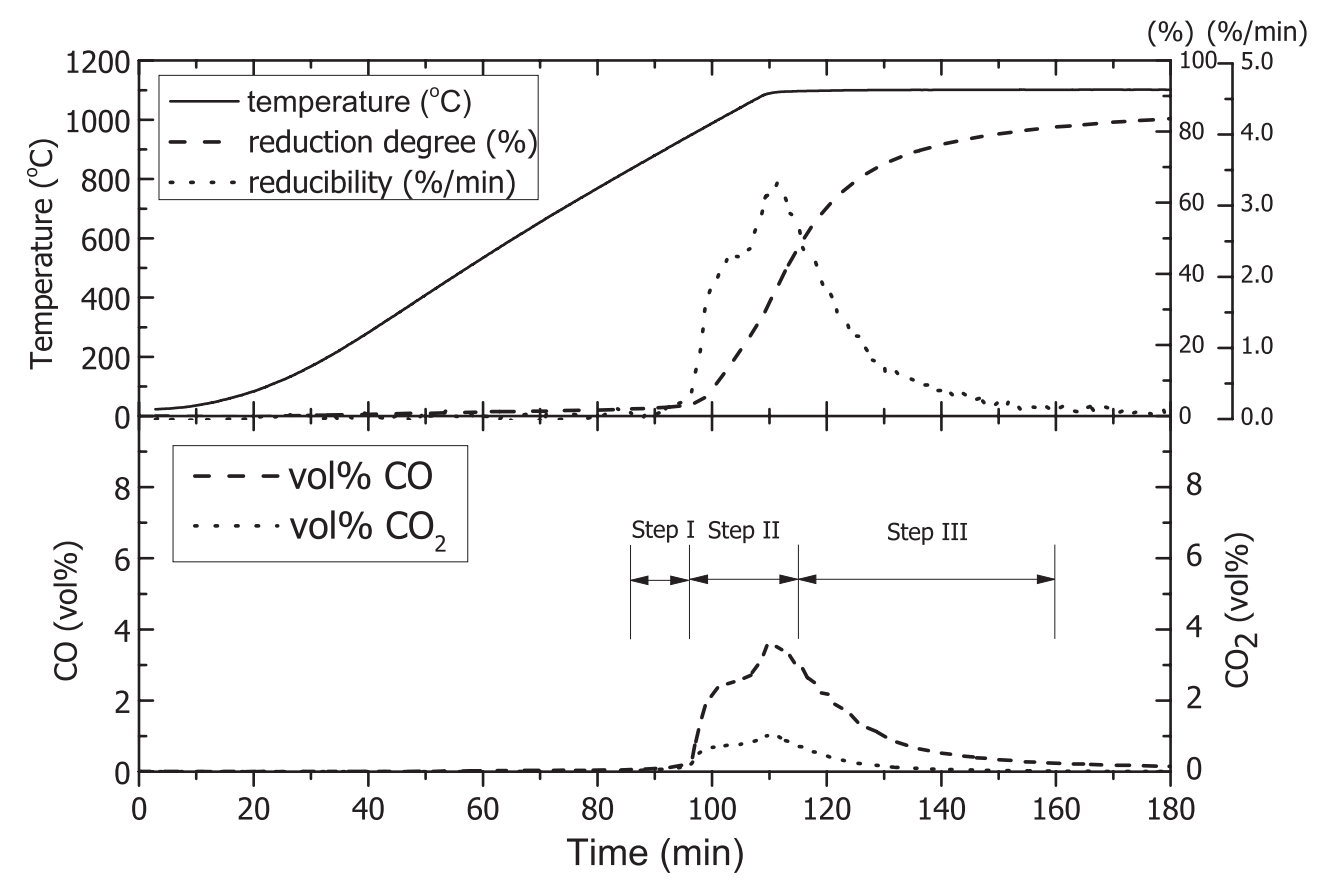

Fig. 2. Non-isothermal reduction of titanomagnetite concentrates by char. 
constant, and at high temperatures because of the depletion of the removal oxygen in the TTM. The entire curve of reduction consists of two parts: the first half shows concave upwards and the remaining part displays concave downwards. The inflection point in between the two corresponds to the highest reduction rate which was confirmed in the reducibility curve in Fig. 2 with increasing temperature to $1100^{\circ} \mathrm{C}$ where the maximum amount of $\mathrm{CO}$ was generated. It is believed that the carbon gasification started to be activated as the temperature approached $1100^{\circ} \mathrm{C},{ }^{12)}$ which provides sufficient $\mathrm{CO}$ gas for reducing TTM.

In relation to the QMS data in Fig. 2, it is impressive that the change of $\mathrm{CO}$ and $\mathrm{CO}_{2}$ curves shows similar patterns. Because there is no reductant source except for carbon in the pellet, the reduction of TTM should be initiated by the direct reduction of Reaction (18) between TTM and char, generating $\mathrm{CO}$ gas at the reaction rate of $k_{1}$. That is, the carbon in char should convert to the intermediate stage of CO formation prior to reacting with the oxide. The $\mathrm{CO}$ then starts to be used for the reduction in TTM to generate $\mathrm{CO}_{2}$ at the reaction rate of $k_{2}$. Generally, the direct reduction contribution involving solid/solid interaction is regarded as relatively small compared with the gaseous reduction. ${ }^{3)}$ The $\mathrm{CO}$ generation rate by gasification can be represented by $k_{3}$ under the assumption that all the $\mathrm{CO}$ gas generated by Eq. (18) or by Eq. (20) was used up for the gaseous reduction of TTM by Eq. (19). In the reduction Step I of Fig. 2 where $\mathrm{CO}$ concentration is almost equal to that of $\mathrm{CO}_{2}$, the carbon gasification does not take place due to the insufficient temperature for gasification, that is, $k_{3}$ is much smaller than $k_{1}$ and $k_{2}, k_{3} \ll k_{1}<k_{2}$. That is, Eq. (20) is the rate-controlling step in the overall reduction process, provided the two-stage mechanism is applicable. However, as the temperature becomes high enough for carbon gasification, that is, the reaction rate constants change its magnitude by $k_{1} \ll k_{2}<$ $k_{3}$, then the reduction reaches the stage where $\mathrm{CO}$ concentration is larger than that of $\mathrm{CO}_{2}$ as shown in Fig. 2. Accordingly, it is believed that the QMS data can clearly provide the valuable clues for the relative rates of the direct reduction between TTM and char, gaseous reduction of TTM by $\mathrm{CO}$ and carbon gasification which constitute the progressive carbothermic reduction of TTM by char.

$$
\begin{aligned}
& \mathrm{TTM}+\mathrm{C}(s) \stackrel{k_{1}}{\rightarrow} \text { reduced } \mathrm{TTM}+\mathrm{CO}(g) \\
& \mathrm{CO}(\mathrm{g})+\mathrm{TTM} \stackrel{k_{2}}{\rightarrow} \text { reduced } \mathrm{TTM}+\mathrm{CO}_{2}(g) \ldots . . \\
& \mathrm{C}(s)+\mathrm{CO}_{2}(g) \stackrel{k_{3}}{\rightarrow} 2 \mathrm{CO}(g)
\end{aligned}
$$

To identify the phase transformations in TTM, XRD analyses were performed for the pellets obtained by non-isothermal reduction experiments. That is, the pellets were heated at a rate of $10^{\circ} \mathrm{C} / \mathrm{min}$ to $500,800,900,1000$ and $1100^{\circ} \mathrm{C}$ and maintained at each temperature for 1 hour and quenched in the progress of reduction. Then the weight of the quenched pellet was measured by an electronic balance. The weight change of the pellet was used to evaluate the fractional reduction and then was provided for XRD analyses as shown in Fig. 3. At 500 and $800^{\circ} \mathrm{C}$, the magnetite in TTM remains unchanged, which shows just the fractional reductions of 0.018 and 0.032 , respectively. Since TTM showed

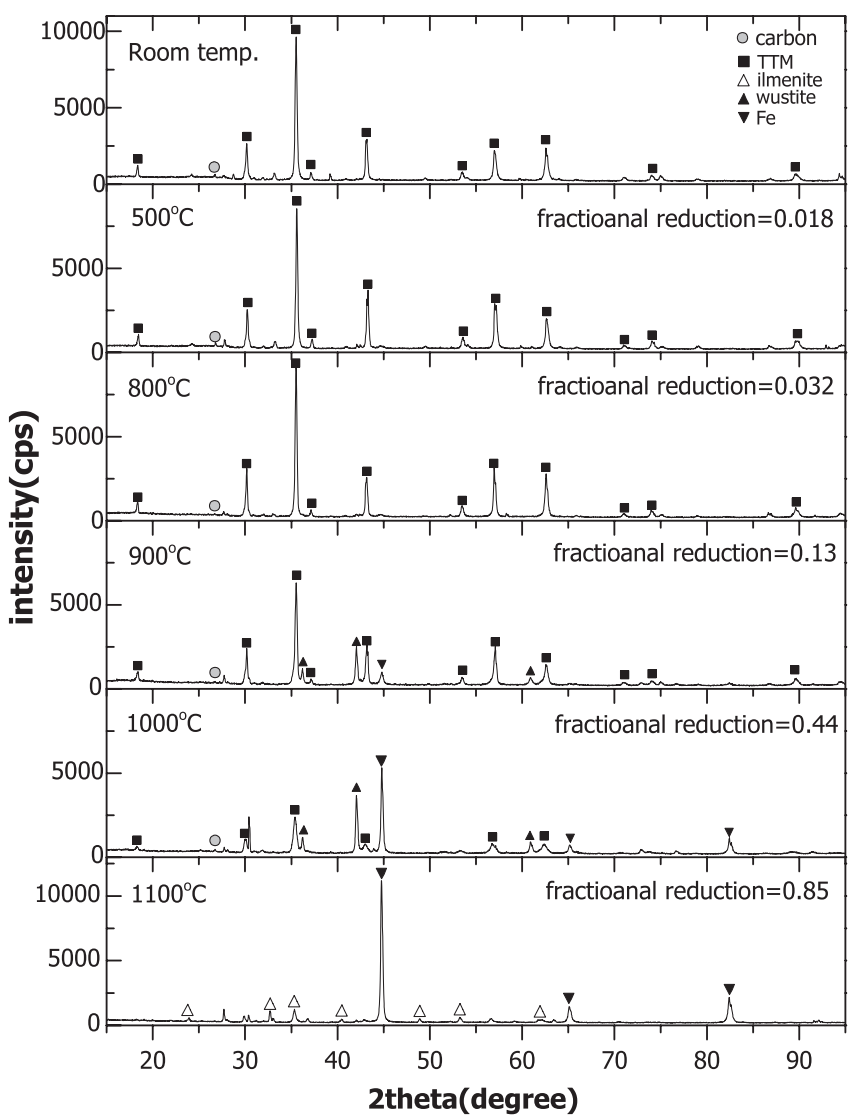

Fig. 3. XRD patterns of titanomagnetite concentrates heated and quenched at different temperatures.

high stability in reducing atmosphere, its traces were observed up to $1000^{\circ} \mathrm{C}$. In addition, the formation of wustite and iron was simultaneously observed at $900^{\circ} \mathrm{C}$. XRD pattern at $1000^{\circ} \mathrm{C}$ indicates that the phases of magnetite, wustite and iron coexist when the fractional reduction is about 0.44 . Thus, it was attempted to calculate the critical fractional reductions for the specific phase transformations. As previously mentioned, TTM is a solid solution of magnetite and ulvospinel. First of all, the fractional reduction can be calculated for the stage where all the $\mathrm{Fe}_{3} \mathrm{O}_{4}$ in TTM reduces to wustite with ulvospinel unchanged considering that $\mathrm{FeO}$ in ulvospinel is not easily reducible since it is tightly bonded with $\mathrm{TiO}_{2}{ }^{10}$ ) The first critical fractional reduction was calculated to be 0.21 as follows:

$$
\begin{aligned}
& \left(\mathrm{Fe}_{3} \mathrm{O}_{4}\right)_{(1-x)}\left(2 \mathrm{FeO} \cdot \mathrm{TiO}_{2}\right)_{x}+(1-x) \mathrm{C} \\
& =3(1-x) \mathrm{FeO}+x\left(2 \mathrm{FeO} \cdot \mathrm{TiO}_{2}\right)+(1-x) \mathrm{CO} \\
& f=\frac{(1-x) \text { moles of } \mathrm{O}}{(4-2 x) \text { moles of } \mathrm{O}}(x=0.28)=0.21 \ldots . .
\end{aligned}
$$

The critical fractional reduction estimated in the current study can be compared with 0.25 for the reduction in $\mathrm{Fe}_{3} \mathrm{O}_{4}$ and graphite composite to wustite. ${ }^{11)}$ The second critical fractional reduction was evaluated to be 0.84 for the reduction stage where all the $\mathrm{Fe}_{3} \mathrm{O}_{4}$ in TTM reduces to metallic Fe with ulvospinel unchanged:

$$
\begin{aligned}
& \left(\mathrm{Fe}_{3} \mathrm{O}_{4}\right)_{(1-x)}\left(2 \mathrm{FeO} \cdot \mathrm{TiO}_{2}\right)_{x}+4(1-x) \mathrm{C} \\
& =3(1-x) \mathrm{Fe}+x\left(2 \mathrm{FeO} \cdot \mathrm{TiO}_{2}\right)+4(1-x) \mathrm{CO}
\end{aligned}
$$




$$
f=\frac{(4-4 x) \text { moles of } \mathrm{O}}{(4-2 x) \text { moles of } \mathrm{O}}(x=0.28)=0.84
$$

Because the fractional reduction of TTM at $1000^{\circ} \mathrm{C}, 0.44$ lies in between 0.21 and 0.84 , the phases of TTM, wustite and metallic Fe can coexist, which was confirmed by XRD analyses. As shown in Fig. 3, traces of ilmenite $\left(\mathrm{FeO} \cdot \mathrm{TiO}_{2}\right)$ were detected at the sample heated to $1100^{\circ} \mathrm{C}$, but $\mathrm{TiO}_{2}$ or $\mathrm{Ti}_{3} \mathrm{O}_{5}$ was not detected, whose fractional reduction was calculated to be about 0.85 by TGA. In addition, the third critical fractional reduction can be calculated for the stage where all the $\mathrm{Fe}_{3} \mathrm{O}_{4}$ in TTM reduces to metallic $\mathrm{Fe}$ and ulvospinel reduces to ilmenite with respect to the reduction completion of TTM and char composite:

$$
\begin{aligned}
& \left(\mathrm{Fe}_{3} \mathrm{O}_{4}\right)_{(1-x)}\left(2 \mathrm{FeO} \cdot \mathrm{TiO}_{2}\right)_{x}+(4-3 x) \mathrm{C} \\
& =(3-2 x) \mathrm{Fe}+x \mathrm{FeO} \cdot \mathrm{TiO}_{2}+(4-3 x) \mathrm{CO} \\
& f=\frac{(4-3 x) \text { moles of } \mathrm{O}}{(4-2 x) \text { moles of } \mathrm{O}}(x=0.28)=0.92 .
\end{aligned}
$$

The fractional reduction of TTM at $1100^{\circ} \mathrm{C}, 0.85$ lies in between 0.84 and 0.92 , which indicates that the ulvospinel in TTM is in the progress of transformation into ilmenite with magnetite in TTM completely reduced to metallic Fe. Since the ulvospinel is thermodynamically unstable compared with ilmenite, it can transform into the phase of ilmenite during quenching from $1100^{\circ} \mathrm{C}$ to ambient temperature. ${ }^{10)}$

\subsection{Evaluation of Fractional Reduction from the View- point of Mass Balance of Carbon}

In order to validate the method of evaluating the fractional reduction in the carbothermic reduction of TTM with char by TGA, it was undertaken to consider the mass balance of carbon in between char and the evolved reaction gases, $\mathrm{CO}$ and $\mathrm{CO}_{2}$ with QMS. The data obtained from QMS was first converted to the flow rates of $\mathrm{CO}$ and $\mathrm{CO}_{2}$ using $\mathrm{Ar}$ as a reference gas under the condition that the flow rate of $\operatorname{Ar}\left(\dot{V}_{\mathrm{Ar}}\right)$ in inlet gas was fixed to be $250 \mathrm{~mL} / \mathrm{min}$. This enabled the conversion of volume percent of $\mathrm{CO}$ and $\mathrm{CO}_{2}$ in the off gas into the flow rates $(\mathrm{mL} / \mathrm{min})$ as follows:

$$
\dot{V}_{\mathrm{i}}=\left(\frac{\operatorname{vol} \% V_{\mathrm{i}}}{\operatorname{vol} \% V_{\mathrm{Ar}}}\right) \times \dot{V}_{\mathrm{Ar}}
$$

where vol\% $V_{\mathrm{i}}$ represents the volume percent of $\mathrm{CO}$ and $\mathrm{CO}_{2}$ in the off gas and vol\% $V_{\mathrm{Ar}}$ stands for the volume percent of $\mathrm{Ar}$ in the off gas. The carbon amounts contained in $\mathrm{CO}$ and $\mathrm{CO}_{2}$ gases was evaluated from the area integrated under the flow rate curves of $\mathrm{CO}$ and $\mathrm{CO}_{2}$ between 0 and 180 min in Fig. 2 as follows:

Carbon in $\mathrm{CO}$ gas $=$

$250.73 \mathrm{~mL} \mathrm{CO} \times \frac{1 \mathrm{~g} \cdot \mathrm{mole} \mathrm{CO}}{22.45128 \times 10^{3} \mathrm{~mL}} \times \frac{1 \mathrm{~g} \cdot \mathrm{mole} \mathrm{C}}{1 \mathrm{~g} \cdot \mathrm{mole} \mathrm{CO}}=0.1340 \mathrm{~g}$

Carbon in $\mathrm{CO}_{2}$ gas $=$

$60.11 \mathrm{~mL} \mathrm{CO} \times \frac{1 \mathrm{~g} \cdot \mathrm{mole} \mathrm{CO}_{2}}{22.45128 \times 10^{3} \mathrm{~mL}} \times \frac{1 \mathrm{~g} \cdot \mathrm{mole} \mathrm{C}}{1 \mathrm{~g} \cdot \mathrm{mole} \mathrm{CO}}=0.0321 \mathrm{~g}$
Accordingly, the total carbon contained in the off gas amounts to $0.1661 \mathrm{~g}$ which is compared with the initial carbon in the original TTM and char pellet, $0.2050 \mathrm{~g}$. The fraction of carbon gasified from the initial carbon in the pellet was calculated to be about 0.81 , which is almost close to the fractional reduction of 0.84 evaluated by TGA in Fig. 2 . Therefore, it is believed that the carbon in char consumed for the reduction in TTM was fully gasified into $\mathrm{CO}$ and $\mathrm{CO}_{2}$ gases, which indicates that the reduction experiment by TGA can be coupled to QMS from the viewpoint of mass balance of carbon.

\subsection{Isothermal Reduction Progress of Titanomagnetite and Char at $1100^{\circ} \mathrm{C}$}

In order to evaluate the rate constants of isothermal reduction of TTM and char composite, the uniform internal reduction model was applied for the reduction of TTM and char composite. ${ }^{5,13)}$ The model was derived under the assumption that the overall reduction rate is controlled by carbon gasification:

$$
\ln (1-f)=-k t
$$

where $f$ represents the fractional reduction and $k$ stands for a rate constant. As shown in Fig. 4, the fastest reduction rate at $1100^{\circ} \mathrm{C}$ was observed around the reduction time when relatively high concentration of $\mathrm{CO}$ gas was generated, which is similar to the case of non-isothermal reduction in Fig. 2. In Fig. 4, the highest rate constant was noticed at the fractional reduction in between 0.20 and 0.30 . As previously confirmed in the non-isothermal reduction experiment, this fractional reduction corresponds to the stage where TTM, magnetite and metallic Fe coexist. The fractional reduction in isothermal carbothermal reduction of TTM at $1100^{\circ} \mathrm{C}$ showed the similar value to the final value obtained in nonisothermal reduction, which strongly indicates that the carbothermic reduction depends on temperature. This indicates that the carbothermic reducibility of TTM is decisively determined by the activation of carbon gasification at the reaction temperature.

The reduction stage where $\mathrm{CO}$ concentration is almost equal to that of $\mathrm{CO}_{2}$ was clearly observed in Fig. 4. As previously pointed out in non-isothermal reduction, this indicates that the CO generated by the Reaction (18) makes critical contribution to the subsequent gaseous reduction of TTM by Eq. (19) while the carbon gasification rate is very slow. In addition, it was observed from QMS data in Fig. 4 that the instantaneous evolution of $\mathrm{CO}$ at the specific time of reduction is higher than that in non-isothermal reduction. It is believed that this is ascribed to the $\mathrm{CO}$ gas generated in large amount in the short time interval by the activation of carbon gasification, which can significantly decrease the reduction time of TTM. In the fractional reduction range from 0.21 to 0.84 , the wustite in TTM started to reduce to metallic Fe by the $\mathrm{CO}$ gas resulted from the carbon gasification activated right after all the magnetite was reduced to wustite. The result can be explained based on the QMS data in Fig. 4. That is, the ratio of $p_{\mathrm{CO}_{2}}$ to $p_{\mathrm{CO}}$ reaches the equilibrium value higher than that for wustite/ $\mathrm{Fe}$ equilibrium at $1100^{\circ} \mathrm{C}$, resulting in the increase of $\mathrm{CO}_{2}$ concentration which subsequently activates the Fe-catalyzed carbon gasification. ${ }^{3,5)}$ This results in generating the strong reducing 


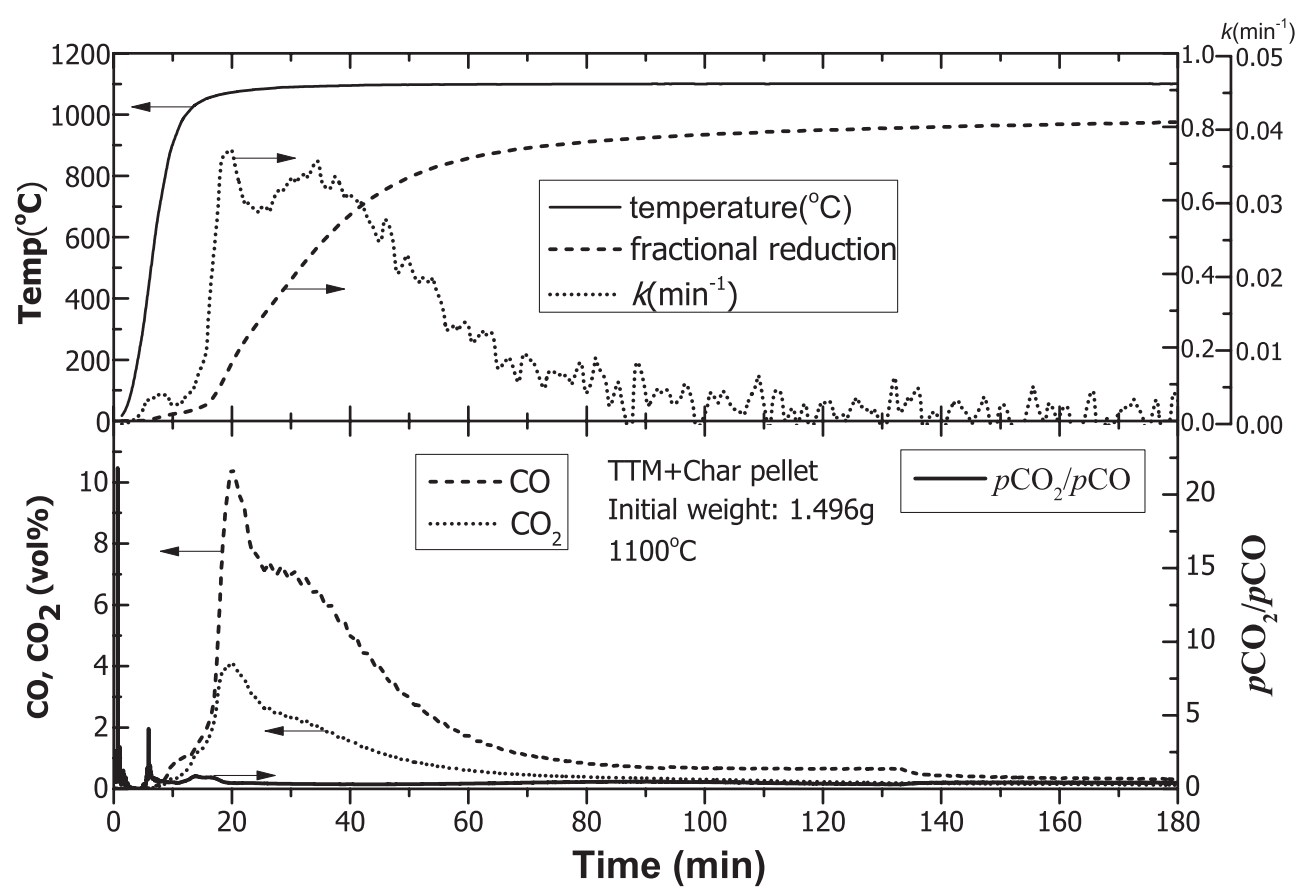

Fig. 4. Isothermal reduction of titanomagnetite concentrates by char at $1100^{\circ} \mathrm{C}$.

CO gas which makes the decisive contribution to attainment of the final fractional reduction higher than 0.80 .

To qualitatively confirm the phase transformations in the reduction progress of titanomagnetite and char composites, the pellets obtained at several fractional reductions were analyzed with X-ray diffraction by isothermal reduction experiments. That is, the pellets were heated at a rate of $100^{\circ} \mathrm{C} / \mathrm{min}$ to $1100^{\circ} \mathrm{C}$ and then withdrawn from TGA and quenched at the specific times in the progress of reduction. Then the weight of the quenched pellet was measured by an electronic balance. The weight change of the pellet was used to calculate the fractional reduction and then was provided for XRD analyses as shown in Fig. 5. The specific fractional reductions were preliminarily selected taking the weight change data of TTM and char reduction at $1100^{\circ} \mathrm{C}$ into account. The XRD patterns in Fig. 5 indicate that the initial pellet consists of magnetite and carbon. The strongest line of magnetite appeared at the diffraction angle of 2 theta $=$ $35.47^{\circ}$ for the crystal plane (311) and that of carbon was detected at $2 \theta=26.60^{\circ}$ for the crystal plane (006). The XRD patterns in Fig. 5 clearly show that the peaks of TTM and wustite are still observed at the fractional reductions of 0.20 and 0.66 while the peak of wustite was not detected at the fractional reduction of 0.81 . It was also noticed that TTM, wustite and metallic Fe coexist at the fractional reduction of 0.20 , which indicates that the pre-reduced wustite can transform into $\mathrm{Fe}$ while some $\mathrm{Fe}_{3} \mathrm{O}_{4}$ in TTM reduces to wustite. As the reduction proceeded, it was clearly observed that the peaks of wustite $\left(\mathrm{Fe}_{0.942} \mathrm{O}\right)$, iron and ilmenite were successively confirmed while the peak intensity of magnetite reduces. In particular, the ilmenite phase was observed only at the fractional reduction of 0.81 even prior to 0.84 corresponding to the reduction stage where the ulvospinel in TTM starts to reduce to ilmenite with magnetite completely reduced to Fe. As already mentioned, it is believed that some ulvospinel phase might have reduced to ilmenite since it is thermodynamically unstable. ${ }^{10)}$ As represented by Eq.

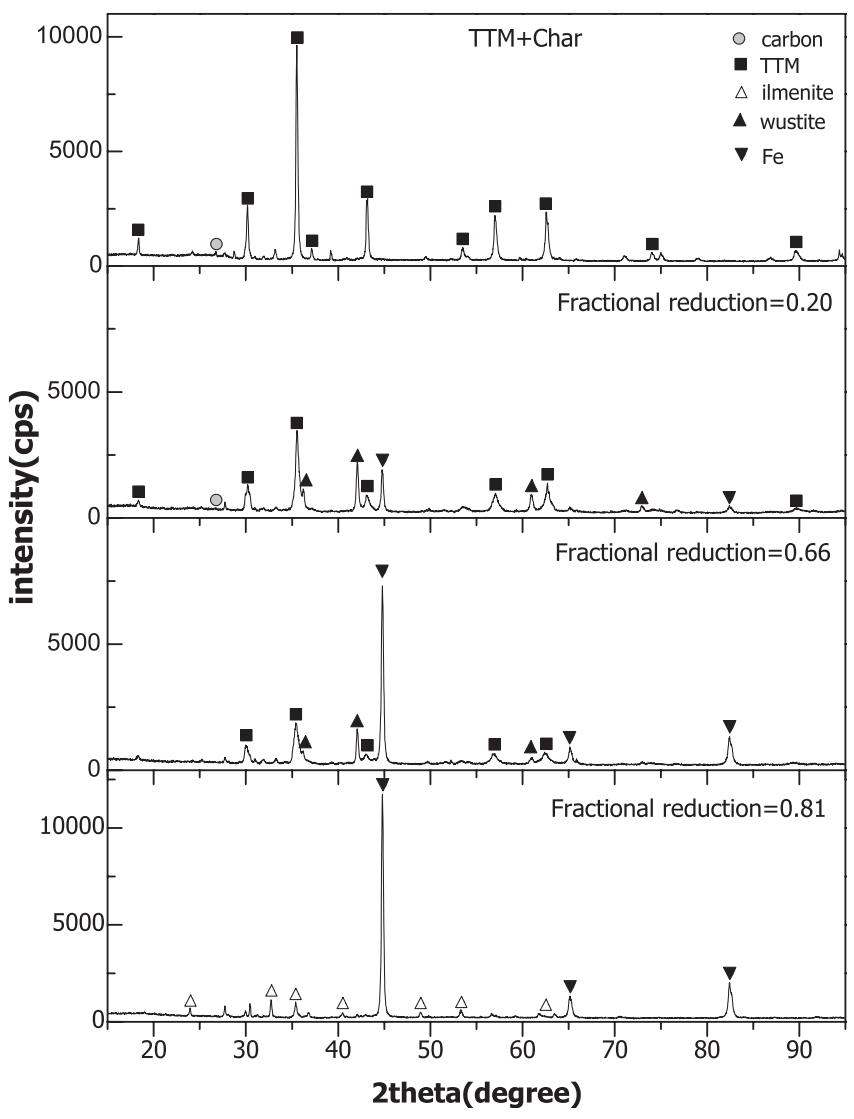

Fig. 5. Progressive change of XRD pattern of titanomagnetite concentrates isothermally reduced by char at $1100^{\circ} \mathrm{C}$.

(33), the ulvospinel in TTM reduced to ilmenite, which was driven by the activation of carbon gasification as represented by Eqs. (31) to (33):

$$
\begin{aligned}
& \left(\mathrm{Fe}_{3} \mathrm{O}_{4}\right)_{(1-x)}\left(2 \mathrm{FeO} \cdot \mathrm{TiO}_{2}\right)_{x}+4(1-x) \mathrm{CO} \\
& \rightarrow 3(1-x) \mathrm{Fe}+x\left(2 \mathrm{FeO} \cdot \mathrm{TiO}_{2}\right)+4(1-x) \mathrm{CO}_{2}
\end{aligned}
$$




$$
\begin{aligned}
& \mathrm{C}(s)+\mathrm{CO}_{2}(g) \rightarrow 2 \mathrm{CO}(g) \ldots \ldots . \\
& x\left(2 \mathrm{FeO} \cdot \mathrm{TiO}_{2}\right)+x \mathrm{CO}(\mathrm{g}) \\
& \rightarrow x \mathrm{Fe}+x\left(\mathrm{FeO} \cdot \mathrm{TiO}_{2}\right)+x \mathrm{CO}_{2}(g)
\end{aligned}
$$

\subsection{Thermodynamic Consideration of the Reduction Progress of TTM and Char and Compositional Change of Reaction Gases}

For in-depth understanding of the carbothermic reduction and reasonable interpretation of the progressive interaction of Fe oxide in TTM with the remaining gangue components, EPMA mapping analysis was performed for the pellet withdrawn in the progress of reduction of which the fractional reduction was estimated to be about 0.20 as shown in Fig. 6. Although $\mathrm{TiO}_{2}$-containing compound is one of the main phases as ulvospinel in TTM, $\mathrm{Fe}_{3} \mathrm{O}_{4}$ in TTM reduced to wustite and $\mathrm{Fe}$ with ulvospinel $\left(2 \mathrm{FeO} \cdot \mathrm{TiO}_{2}\right)$ unreduced while maintaining its original site within TTM by the Reaction (34).

$$
\begin{gathered}
\mathrm{Fe}_{3} \mathrm{O}_{4}(s)+\mathrm{C}(s)=3 \mathrm{FeO}(s)+\mathrm{CO}(g) \\
\Delta G^{\circ}=199400-202.0 T(\mathrm{~J} / \mathrm{mol})^{14)}
\end{gathered}
$$

If $\mathrm{SiO}_{2}$ could exist in TTM as confirmed in Table 1, the formation of fayalite would make the reduction harder accord- ing to the following thermodynamic data with increasing temperature higher than $1100^{\circ} \mathrm{C}$ :

$$
\begin{gathered}
2 \mathrm{FeO}(s)+\mathrm{SiO}_{2}(s)=2 \mathrm{FeO} \cdot \mathrm{SiO}_{2}(s) \\
\Delta G^{\circ}=-36200+21.1 T(\mathrm{~J} / \mathrm{mol})^{15)} .
\end{gathered}
$$

However, if TTM could contain some $\mathrm{CaO}, \mathrm{SiO}_{2}$ might prefer to combine with $\mathrm{CaO}$ to form calcium silicate which is the most stable compound at this temperature. This formation of calcium silicate will improve wustite reduction by liberating wustite entrapped in the fayalite phase. ${ }^{16)}$

$$
\begin{gathered}
\mathrm{CaO}(s)+\mathrm{SiO}_{2}(s)=\mathrm{CaO} \cdot \mathrm{SiO}_{2}(s) \\
\Delta G^{\circ}=-92500+2.5 T(\mathrm{~J} / \mathrm{mol})^{15)}
\end{gathered}
$$

In addition, it was noticed in Fig. 6 that $\mathrm{MgO}$ oxide was detected at the similar region to wustite, which indicates that the solid solution of magnesiowustite, $(\mathrm{Mg}, \mathrm{Fe}) \mathrm{O}$ might be formed in the reduction progress of $\mathrm{Fe}_{3} \mathrm{O}_{4}$ in TTM to wustite if TTM contains some $\mathrm{MgO}$ in it since $\Delta G^{\circ}$ for the formation of the magnesiowustite is negative at $1100^{\circ} \mathrm{C}$ according to FactSage calculation. ${ }^{17}$ ) This indicates that $\mathrm{MgO}$ in TTM might retard the reduction of wustite, which might be one of the reasons for the incomplete reduction of TTM at $1100^{\circ} \mathrm{C}$.

As is evident in the current study, it is believed that the

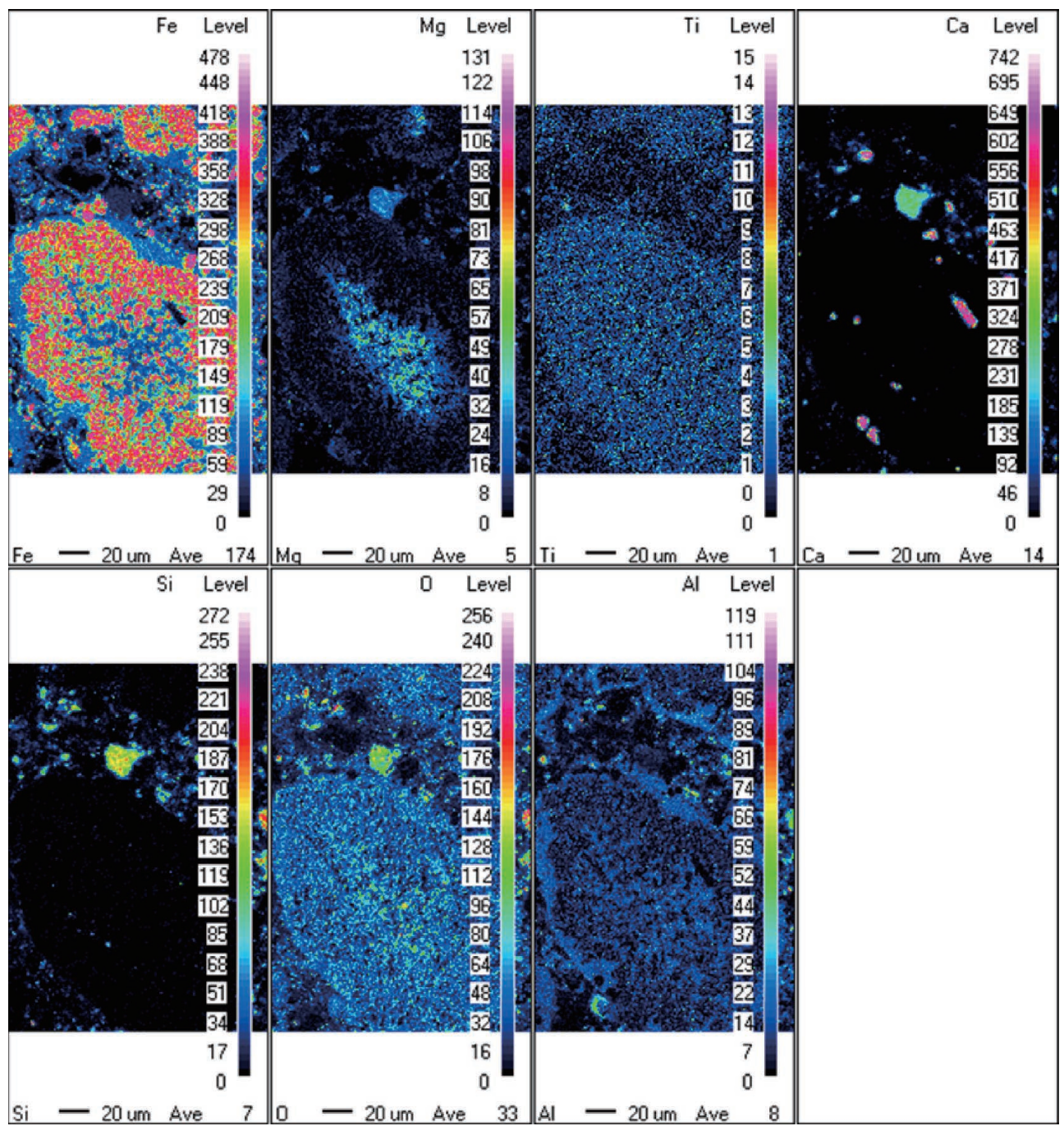

Fig. 6. EPMA mapping of the TTM in the middle of reduction. 
initial formation of $\mathrm{CO}$ is ascribed to direct solid-solid reaction between TTM and char. The gaseous reduction of TTM and char gasification proceed in parallel and affect each other through the compositional change of $\mathrm{CO}$ and $\mathrm{CO}_{2}$ gases. ${ }^{3,5)}$ Because the clear knowledge of the gas composition will improve the understanding of the kinetics and mechanism of isothermal reduction of TTM, it was attempted to plot the compositional change of $\mathrm{CO}$ in the mixture of $\mathrm{CO}$ and $\mathrm{CO}_{2}$ obtained in the isothermal heating stage at $100^{\circ} \mathrm{C} / \mathrm{min}$ up to $1100^{\circ} \mathrm{C}$ in $\mathrm{Fe}-\mathrm{O}-\mathrm{C}$ diagram as shown in Fig. 7. According to the compositional change of reaction gas by QMS in Fig. 7, the reduction progress can be classified into two stages. First of all, the first stage represents that the reduction of TTM dominates the entire reduction of TTM and char composite. This stage indicates that $\mathrm{CO}$ in the atmosphere slightly decreases while the TTM and char pellet was being heated in the temperature range of 400 to $970^{\circ} \mathrm{C}$. This clearly indicates that the $\mathrm{CO}$ gas generated by the solid direct reduction between TTM and char was used to reduce the TTM around it while the char gasification does not almost activate as previously shown in Fig. 4. The CO proportion in the first stage continuously decreases due to $\mathrm{CO}_{2}$ gas generated by the reduction in TTM to wustite, which results in reaching the local minimum amount of $\mathrm{CO}$ gas at about $970^{\circ} \mathrm{C}$ :

$$
\mathrm{TTM}+\mathrm{C}=(\mathrm{TTM}+\text { wustite })+(\text { ulvospinel })+\mathrm{CO}(g)
$$

$$
\mathrm{CO}(g)+\mathrm{TTM}=(3 \mathrm{FeO})+(\text { ulvospinel })+\mathrm{CO}_{2}(g)
$$

Finally, the second stage represents the rapid generation of $\mathrm{CO}$ gas by the activation of Fe-catalyzed carbon gasification. As of this instant, the reduction rate of TTM and char pellet starts to be accelerated towards the equilibrium concentration of $\mathrm{CO}$ determined by the gasification curve in Fig. 7, which plays the decisive role in reducing the wustite into metallic Fe and in reducing ulvospinel to ilmenite as represented by Eqs. (43) and (44). After the gases passes the equilibrium composition between wustite/Fe reduction, the

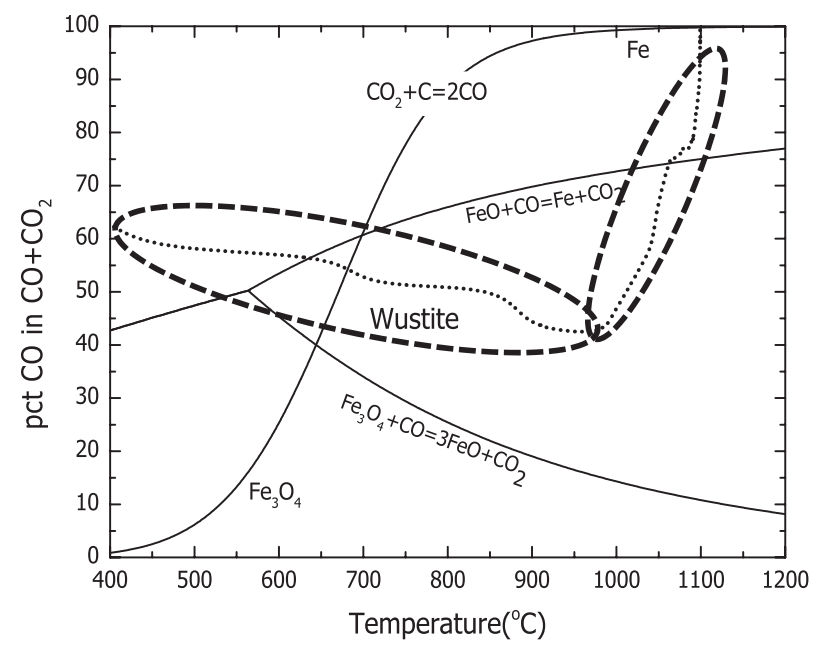

Fig. 7. Compositional change of reaction product gas in the isothermal reduction progress of TTM + char pellet at $1100^{\circ} \mathrm{C}$ plotted in the $\mathrm{Fe}-\mathrm{O}-\mathrm{C}$ equilibrium diagram containing the carbon gasification curve. composition approaches pure $\mathrm{CO}$ by carbon gasification since no more removable oxygen in TTM remains left for reduction. Therefore, Fig. 7 indirectly indicates that the temperature higher than about $970^{\circ} \mathrm{C}$ and some accumulation of $\mathrm{CO}_{2}$ gas are required for the activation of carbon gasification, which results in the rapid reduction in wustite to $\mathrm{Fe}$ and that in ulvospinel to ilmenite.

$$
\begin{aligned}
& \mathrm{CO}_{2}(g)+\mathrm{C}(s) \rightarrow 2 \mathrm{CO}(g) \\
& 3(1-x) \mathrm{FeO}+3(1-x) \mathrm{CO} \rightarrow 3(1-x) \mathrm{Fe}+3(1-x) \mathrm{CO}_{2} \\
& x\left(2 \mathrm{FeO} \cdot \mathrm{TiO}_{2}\right)+x \mathrm{CO} \rightarrow x \mathrm{Fe}+x\left(\mathrm{FeO} \cdot \mathrm{TiO}_{2}\right)+x \mathrm{CO}_{2}
\end{aligned}
$$

\subsection{Effect of Temperature on the Isothermal Reduc- tion}

The isothermal reduction experiments were performed at four different temperatures in the range of 1000 to $1150^{\circ} \mathrm{C}$ as shown in Fig. 8. That is, the isothermal experiments at different temperatures have been maintained until the fractional reduction at each temperature reached a constant value. The change of fractional reduction at each temperature shows the similar pattern to those previously reported. ${ }^{18)}$ That is, the reduction process can be classified into several stages. The reduction reaction at the initial stage proceeded quite slowly up to the fractional reduction of about 0.05 , which indicates that it took about $15 \mathrm{~min}$ to reach the thermal equilibrium inside the pellet. However, the reduction rate in the second stage became extremely fast where the reduction curve changes its curvature from concave up to concave down across the fractional reduction of about 0.20 . In the final reduction stage, the reduction rate becomes slow again due to the depletion of removal oxygen combined with $\mathrm{Fe}$ and due to the tight bonding of wustite in ulvospinel since the oxygen removal is relatively difficult from the phase of ulvospinel.

To qualitatively identify the phases in the reduced titanomagnetite by char in the temperature range of 1000 to $1150^{\circ} \mathrm{C}$, the pellets obtained by isothermal reduction experiments at four temperatures were analyzed with X-ray dif-

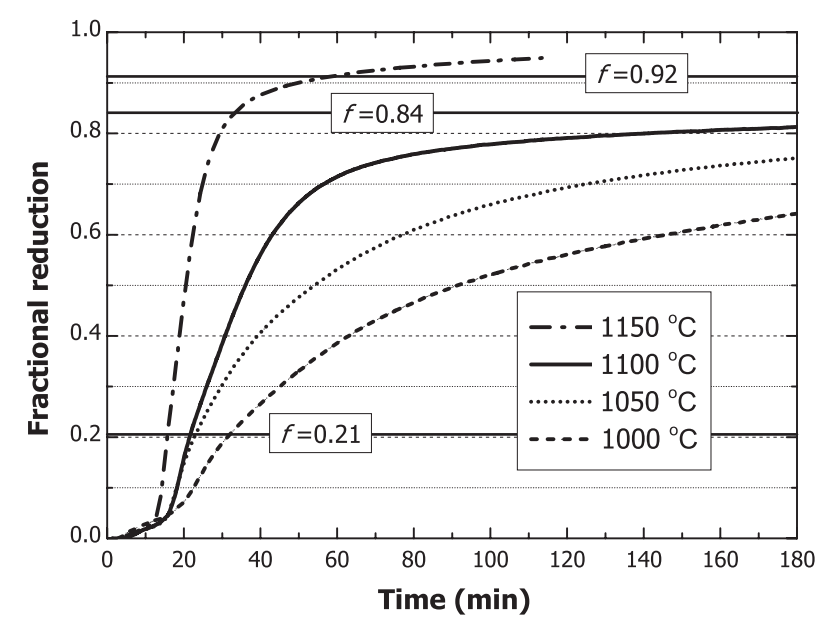

Fig. 8. Effect of temperature on isothermal reduction of titanomagnetite by char. 
fraction as shown in Fig. 9. The closer observation of data in Fig. 8 showed that the isothermal reduction at 1000 and $1050^{\circ} \mathrm{C}$ reached the fractional reduction lower than 0.80 , which was confirmed by XRD patterns in Fig. 9. That is, any peak of ilmenite was not detected at the ranges of fractional reduction, as previously explained. However, the reduction at 1100 and $1150^{\circ} \mathrm{C}$ attained the fractional reduction higher than 0.80 where ilmenite was identified as shown in Fig. 9. In particular, it took just about $10 \mathrm{~min}$ for the reduction to increase from 0.21 to 0.84 at $1150^{\circ} \mathrm{C}$, and the fractional reduction reached about 0.95 in $90 \mathrm{~min}$. The outstanding reduction patterns of TTM with char at 1100 and $1150^{\circ} \mathrm{C}$ are ascribed to the activated gasification of the char used in the current study. This is because the critical temperature for the gasification of the char was found to be $1055^{\circ} \mathrm{C}$ according to the preliminary thermal analysis. That is, $100 \mathrm{mg}$ of TTM and char composite was continuously heated at $10^{\circ} \mathrm{C} / \mathrm{min}$ to $1100^{\circ} \mathrm{C}$ by the differential scanning calorimetry (DSC) measurement together with TGA analysis. Based on the critical weight change in TGA and the endothermic peak of the char gasification reaction, the activation temperature of the char gasification was identified to be $1055^{\circ} \mathrm{C}$. Furthermore, it is well known that $1100^{\circ} \mathrm{C}$ is the critical temperature above which the carbon gasification reaction goes to completion, which is also found in Fig. $7 .^{12)}$ Therefore, it is well understood that the carbothermic reduction rate of TTM with char strongly depends on the temperature where the carbon gasification reaction can positively be activated.

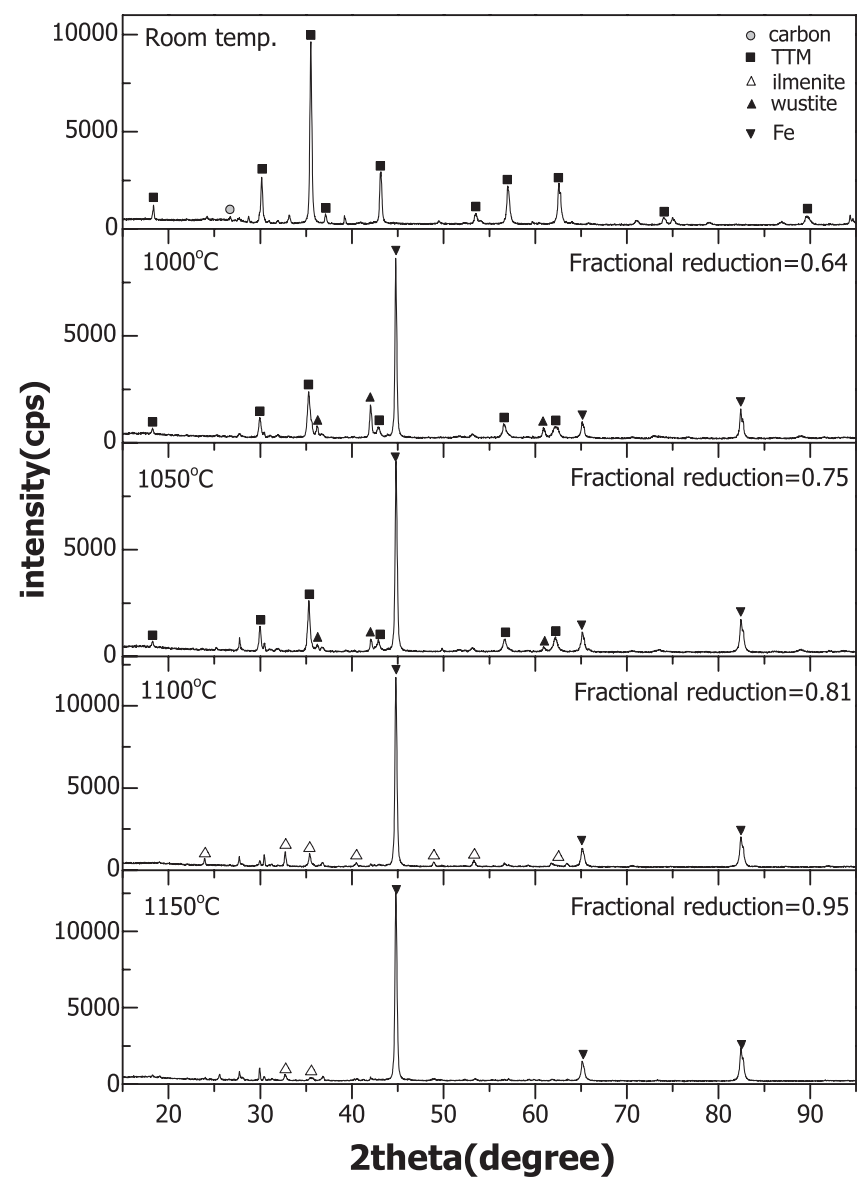

Fig. 9. XRD patterns of titanomagnetite isothermally reduced by char at different temperatures.
In general, the reduction becomes increasingly diffusion controlled since chemical reaction has higher activation energy than gaseous diffusion. ${ }^{12)}$ This indicates that the activation energy decreases in the chemical control region increasing fractional reduction. ${ }^{4)}$ In order to estimate the activation energies for the reduction in TTM to metallic Fe, the rate constants of the reduction in TTM and char were evaluated from uniform internal reduction model by Eq. (30). ${ }^{5,13)}$ Then, the activation energy can be calculated by plotting the temperature dependence of the rate constant:

$$
k=k_{0} \exp \left(-E_{A} / R T\right)
$$

where $k$ is a rate constant, and $E_{A}$ is the activation energy. Differentiating the data of $\ln (1-f)$ with reduction time in the temperature range of 1000 to $1150^{\circ} \mathrm{C}$ provided the largest rate constant at each temperature. The apparent rate constants in the stages for the reduction in $\mathrm{Fe}_{3} \mathrm{O}_{4}$ to wustite and for that in wustite to $\mathrm{Fe}$ were also plotted in the period of time corresponding to each reduction stage using the previously reported data ${ }^{11}$ about the carbothermic reduction of $\mathrm{Fe}_{3} \mathrm{O}_{4}$ with graphite as shown in Fig. 10.

As is clear from the results in Fig. 10, the activation energy value of $241 \mathrm{~kJ} / \mathrm{mol}$ evaluated in the current study can be compared with the previously reported activation energies $(215-310 \mathrm{~kJ} / \mathrm{mol})$ for the carbon gasification. ${ }^{7)}$ In general, it has been reported that $\mathrm{CO}$ consumption rate in the reduction of iron ore is larger than $\mathrm{CO}$ generation rate by non-catalytic oxidation of coke. ${ }^{13)}$ It is believed that the reduction in TTM by char is limited by the carbon gasification in the reduction stage of $\mathrm{Fe}_{3} \mathrm{O}_{4}$ in TTM to wustite. ${ }^{7)}$ On the other hand, $94 \mathrm{~kJ} / \mathrm{mol}$ of the activation energy in the stage for the reduction in wustite to metallic $\mathrm{Fe}$ was obtained for the reduction of $\mathrm{Fe}_{3} \mathrm{O}_{4}$ with graphite as shown in Fig. 10. ${ }^{11)}$ This value is slightly smaller than those by $\mathrm{CO}$ gas which ranges from 116 to $151 \mathrm{~kJ} / \mathrm{mol}^{19-21)}$ In addition, this value is much smaller than that for the reduction in $\mathrm{Fe}_{3} \mathrm{O}_{4}$ of TTM to wustite, which is in good agreement with the previous results. ${ }^{22)}$ That is, lower activation energy values at higher fractional reduction are apparent since the activation energy decreases with increasing the reduction of iron oxide. ${ }^{4}$ Therefore, it is believed that the high activation energy value $(241 \mathrm{~kJ} / \mathrm{mol})$ might be associated with the gas-

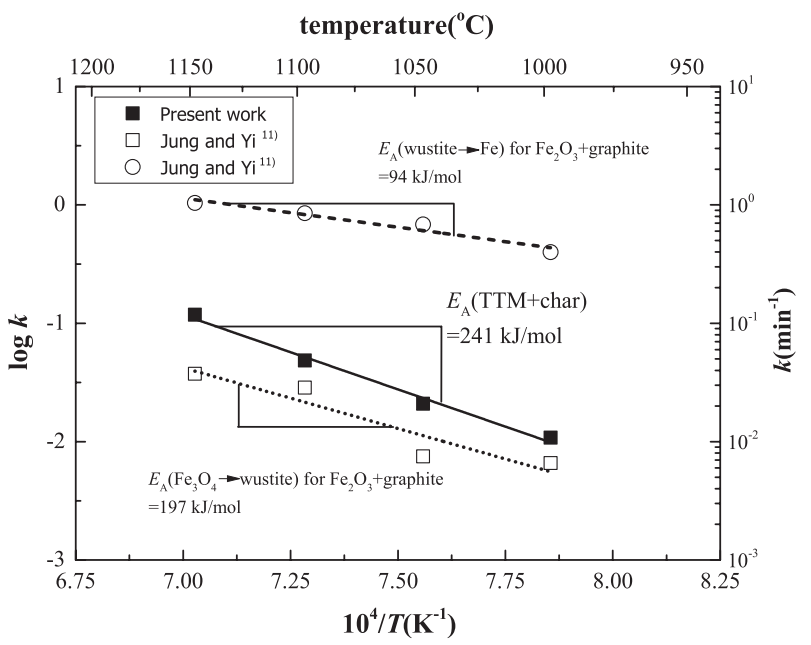

Fig. 10. Temperature dependence of apparent rate constants for reduction in TTM by char. 
ification reaction and the lower value $(94 \mathrm{~kJ} / \mathrm{mol})$ with the reduction of iron oxide by $\mathrm{CO}$. These observations suggest a possible change over in mechanism accompanied by variations in specific reaction rate constants during the progress of reduction.

\subsection{Changeover of Reaction Mechanism during Iso- thermal Reduction Progress}

In case some specific reaction mechanism is identified and non-isothermal reduction progresses, the slopes of the lines of temperature dependence of reduction rate in the chemical control region decrease with increasing the reduction degree. ${ }^{12)}$ That is, the reduction becomes increasingly diffusion controlled during the reduction progress. The changeover of reaction mechanism identified from nonisothermal reduction was considered for the isothermal carbothermic reduction of TTM with char.

According to the experimental results, the changeover in reduction mechanism of TTM and char can schematically be expressed by Fig. 11. In the low fractional reductions where carbon gasification is not activated yet, the carbon gasification reaction can be rate-controlling. As the reduction progresses, the rate of carbon gasification is close to that of the reduction of $\mathrm{Fe}_{3} \mathrm{O}_{4}$ in TTM to wustite and then the rate of carbon gasification becomes higher than that of wustite reduction to metallic Fe. As shown in the current study, in the reduction progress up to the fractional reduction of 0.21 , the rate is controlled by carbon gasification, and then the final stage is under mixed control between reduction of wustite to metallic $\mathrm{Fe}$ and carbon gasification from the relative magnitude of the activation energy. However, in case the isothermal reduction of TTM and char pellet is carried out at temperatures where the carbon gasification reaction is activated to some degree due to the action of some catalysts in the pellet, the carbon gasification may not be rate controlling throughout the course of reduction, the final stages being probably controlled by the reduction of wustite in TTM by CO. This indicates that the carbothermic reduction rate of TTM can be accelerated by adding some additives which make critical contribution to the decisive improvement of carbon gasification even from the initial reduction stage at lower temperatures as possible.

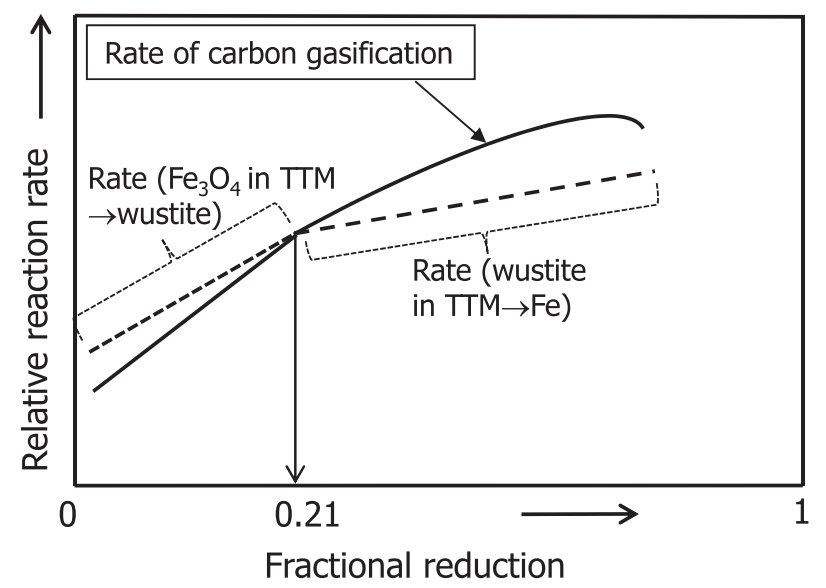

Fig. 11. Changeover of reaction mechanism in the progress of isothermal carbothermic reduction of titanomagnetite with char at $1100^{\circ} \mathrm{C}$.

\section{Conclusions}

The carbothermic reduction in titanomagnetite by char has been investigated from a kinetic viewpoint employing thermogravimetric measurement technique and QMS gas analysis in the temperature range of 1000 to $1150^{\circ} \mathrm{C}$. From the findings, the following conclusions were obtained.

(1) The titanomagnetite mined in New Zealand is a solid solution of magnetite and ulvospinel where the mole fraction of ulvospinel was evaluated to be 0.28 .

(2) The QMS data can clearly provide the valuable clues for the relative rates of the direct reduction between TTM and char, gaseous reduction of TTM by CO and carbon gasification, which constitute the progressive carbothermic reduction of TTM by char.

(3) The carbon in char consumed for the reduction of TTM was fully gasified into $\mathrm{CO}$ and $\mathrm{CO}_{2}$, which indicates that the reduction experiment by TGA can reasonably be coupled to QMS from the viewpoint of mass balance of carbon.

(4) In the reduction progress of TTM and char pellet, it was observed that the carbon gasification reaction was activated when the $\mathrm{Fe}_{3} \mathrm{O}_{4}$ in TTM, wustite and $\mathrm{Fe}$ coexist, i.e. at the fractional reduction of 0.21 , indicating that Fe-catalyzed nature for carbon gasification reaction was confirmed.

(5) Considering that the activation energy of $241 \mathrm{~kJ} / \mathrm{mole}$ for the reduction in TTM and char was evaluated in the temperature range of 1000 to $1150^{\circ} \mathrm{C}$, it is believed that the reduction in TTM by char is limited by the carbon gasification in the reduction stage of $\mathrm{Fe}_{3} \mathrm{O}_{4}$ in TTM to wustite.

(6) In case the isothermal reduction of TTM and char pellet is carried out at temperatures where the carbon gasification reaction is activated to some degree, the carbon gasification may not be rate controlling throughout the course of reduction.

\section{REFERENCES}

1) S. Inaba: Tetsu-to-Hagané, 87 (2001), 221.

2) F. Globler and R. C. A. Minnitt: J. South African Inst. of Min. Metall., 99 (1999), 111.

3) Y. K. Rao: Metall. Trans., 2 (1971), 1439.

4) N. S. Srinivasan and A. K. Lahiri: Metall. Trans. B, 8B (1977), 175.

5) R. J. Fruehan: Metall. Trans. B, 8B (1977), 279.

6) T. Szendrei and P. C. V. Berge: Thermochimica Acta, 44 (1981), 11.

7) T. Coetsee, P. C. Pistorius and E. E. de. Villiers: Miner. Eng., 13 (2002), 919.

8) J. Yang, T. Mori and M. Kuwabara: ISIJ Int., 47 (2007), 1394.

9) D. Chen, B. Song, L. Wang, T. Qi, Y. Wang and W. Wang: Miner. Eng., 24 (2011), 864.

10) E. Park and O. Ostrovski: ISIJ Int., 43 (2003), 1316.

11) S.-M. Jung and S. H. Yi: Ironmaking Steelmaking, 40 (2013), in press.

12) A. K. Viswas: Principles of Blast Furnace Ironmaking, SBA Pub., Calcutta, India, (1981), 37, 65, 74, 234.

13) E. T. Turkdogan: Metall. Trans. B, 9B (1978), 163.

14) D. R. Gaskell: Introduction to Thermodynamics of Materials, 4th ed., Taylor \& Francis, Washington DC, (2003), 582.

15) R. J. Fruehan: The Making, Shaping and Treating of Steel, Steelmaking and Refining Volume, 11th ed., AISE Steel Foundation, Pittsburgh, (1998), 20.

16) S. J. Bai, S. M. Wen, D. W. Liu, W. B. Zhang and Y. J. Xian: ISIJ Int., 51 (2011), 1601.

17) C. W. Bale, E. Bélisle, P. Chartrand, S. A. Decterov, G. Eriksson, K. Hack, I.-H. Jung, Y.-B. Kang, J. Melançon, A. D. Pelton, C. Robelin and S. Petersen: Calphad, 33 (2009), 295.

18) Y. Iguchi and Y. Takada: ISIJ Int., 44 (2004), 673.

19) K. L. Trushenski and W. O. Philbrook: Metall. Trans., 5 (1974), 1149.

20) T. Murayama, Y. Ono and Y. Kawai: Trans. Iron Steel Inst. Jpn., 18 (1978), 579.

21) E. T. Turkdogan and J. V. Vinters: Metall. Trans., 3 (1972), 1561.

22) K. Otsuka and D. Kunii: J. Chem. Eng. Jap., 2 (1969), 46. 